Научная статья

УДК 338.22

DOI: 10.18101/2307-3330-2021-1-86-92

\title{
РАЗВИТИЕ ФИНАНСОВОЙ ГРАМОТНОСТИ В КОНТЕКСТЕ РЕШЕНИЯ ПРОБЛЕМЫ ЗАКРЕДИТОВАННОСТИ НАСЕЛЕНИЯ РЕСПУБЛИКИ БУРЯТИЯ
}

\author{
(c) Маланов Виталий Иннокентьевич \\ магистрант, \\ Бурятский государственный университет им. Доржи Банзарова \\ Россия, 670000, г. Улан-Удэ, ул. Смолина, 24а \\ mvi_mmv@mail.ru
}

\begin{abstract}
Аннотация. Статья посвящена актуальной задаче развития финансовой грамотности в контексте решения проблемы закредитованности населения Республики Бурятия. Авторами исследуются существующие методологические подходы к определению данного понятия; показатели, характеризующие закредитованность населения. В статье рассмотрены причины закредитованности, при этом особое внимание уделено одной из основных проблем - низкому уровню финансовой грамотности его населения. Автором предложен комплекс мероприятий, способствующих решению проблемы закредитованности населения Республики Бурятия.

Ключевые слова: финансовая грамотность, закредитованность населения, социально-экономическое развитие, уровень жизни, среднедушевые доходы, среднемесячная номинальная начисленная заработная плата, индекс потребительских цен, показатель долговой нагрузки заемщиков (ПДН)
\end{abstract}

\section{Для цитирования}

Маланов В. И. Развитие финансовой грамотности в контексте решения проблемы закредитованности населения Республики Бурятия // Вестник Бурятского государственного университета. Образование. Личность. Общество. 2021. Вып. 1. С. 86-92.

В настоящее время в России обострилась проблема обслуживания населением своей кредитной задолженности в коммерческих банках и небанковских кредитных организациях.

По состоянию на сентябрь 2015 г. Республика Бурятия находилась на третьем месте среди регионов Сибирского федерального округа и на девятом месте по Российской Федерации с самым закредитованным населением - уровень закредитованности населения составил на тот момент $36 \%$, средняя кредитная задолженность домохозяйства $-320,5$ тыс. р., в т. ч. просроченная $-5,5 \%$. В настоящее время ситуация несколько улучшилась - Бурятия по итогам 2020 г. занимала 48-е место в рейтинге регионов Российской Федерации и 9-е (из 11) в рейтинге регионов Дальневосточного федерального округа по уровню закредитованности, соотношение среднедушевого долга по кредитам и годовой зарплаты в Бурятии в 2020 г. составило 58,0\%, объем задолженности перед банками в среднем на одного человека - 246,6 тыс. p. 
В. И. Маланов. Развитие финансовой грамотности в контексте решения проблемы закредитованности населения Республики Бурятия

Под закредитованностью авторами понимается высокий уровень задолженности по совокупным кредитам, при котором размеры выплат по кредитам превышают определенное отношение к доходам заемщика. При этом отношение размера выплат по кредитам к доходам заемщика принято называть долговой нагрузкой. Особый интерес представляют подходы к оценке показателя долговой нагрузки. В международной практике широкое распространение получили два показателя долговой нагрузки - DTI (debt to income) и PTI (payment to income).

Показатель DTI рассчитывается как отношение совокупной задолженности заемщика по кредитам и займам к доходу заемщика. Показатель DTI не учитывает будущие (еще не начисленные) процентные платежи по кредитам.

$$
D T I=\frac{\sum_{i=1}^{N} \text { Задолженность } i}{\text { Доход за } 12 \text { месяцев }} * 100 \% \text {, }
$$

где Задолженность ${ }_{i}$ - задолженность заемщика по $i$-му кредиту/займу на дату расчета показателя DTI. В случае наличия у заемщика действующей кредитной карты в состав параметра Задолженность также включается установленный лимит по карте; $N$ - общее количество действующих кредитных договоров (займов) у заемщика на дату расчета показателя DTI; Доход за 12 месяцев - доход заемщика за 12 месяцев, рассчитанный на дату, отстоящую от даты расчета показателя DTI не более чем на шесть календарных месяцев. В качестве источников, подтверждающих доход заемщика, могут выступать сведения из Пенсионного фонда России, выписка по счету заемщика для тех кредитных организаций, в которых у клиента открыт зарплатный счет, справка по форме 2-НДФЛ.

Показатель PTI, который в России называется «показателем долговой нагрузки заемщиков» (ПДН), соотносит размер ежемесячного платежа заемщика по всем имеющимся у него кредитам (основной долг и проценты) с его среднемесячным доходом. Несмотря на ряд преимуществ, расчет показателя PTI требует больших операционных затрат от финансовых организаций. Кроме того, при расчете показателя возникают сложности с определением плановых платежей по кредитным картам, так как в бюро кредитных историй (БКИ) может отсутствовать информация о размере минимального платежа по карте.

$$
P T I=\frac{\sum_{i=1}^{N} \text { Среднемесячный платеж }}{\text { Среднемесячный доход за } 12 \text { месяцев }} * 100 \%,
$$

где Среднемесячный платежі - среднемесячный платеж по $i$-му кредиту/займу на дату расчета показателя PTI, определенный исходя из оставшегося графика до погашения $i$-го кредита/займа. По кредитам/займам, которые были предоставлены финансовой организацией, осуществляющей расчет показателя PTI, среднемесячный платеж определяется в соответствии с условиями договора. По кредитам/займам, которые были предоставлены организациями, отличными от организации, осуществляющей расчет показателя PTI, среднемесячный платеж рассчитывается по следующей формуле: 
Среднемесячный доход за 12 месяцев - доход заемщика за 12 месяцев, разделенный на двенадцать и рассчитанный на дату, отстоящую от даты расчета показателя PTI не более чем на шесть календарных месяцев.

$\mathrm{N}$ - аналогично расчету показателя DTI;

$$
\text { Среднемесячный платеж }{ }_{\mathrm{i}}=\frac{\frac{\Pi C \mathrm{~K}_{\mathrm{i}}}{12} \text { Задолженность }}{1-\left(1+\frac{\Pi \mathrm{CK} \mathrm{K}_{\mathrm{i}}}{12}\right)^{-\mathrm{T}_{\mathrm{i}}}} \text {, }
$$

где ПСК - полная стоимость і-го кредита/ займа.

Задолженность - ссудная задолженность по і-му кредиту/займу на момент расчета значения показателя РТI;

$\mathrm{T}_{\mathrm{i}}$ - количество месяцев, оставшихся до погашения i-го кредита/займа. По кредитам, предоставленным с использованием кредитных карт, среднемесячный платеж рассчитывается исходя из максимально возможных суммы кредита и сроков возврата кредита в соответствии с вышеприведенной формулой расчета среднемесячного платежа.

По своему содержанию DTI ориентирован на контроль уровня совокупной долговой нагрузки гражданина, а PTI - на контроль уровня его ежемесячного располагаемого дохода. При этом каждый из показателей имеет сложности в применении. Недостатком DTI является чрезмерное влияние на него крупных кредитов (например, ипотечных), препятствующих привлечению последующих кредитов даже при наличии многолетней рассрочки и низких аннуитетных платежей. В свою очередь, недостатком PTI является невозможность учета (при однократном расчете PTI на момент выдачи кредита) динамики изменений в суммах ежемесячных платежей заемщика (при неаннуитетных выплатах по обязательствам) и/или изменений ежемесячного дохода, а также необходимость дифференциации величины показателя РТI в зависимости от абсолютной суммы дохода гражданина (по общему правилу чем больше доход, тем больше величина допустимого PTI). При этом для расчета обоих показателей требуются практически идентичные источники достоверной, полной и актуальной информации о доходах граждан, отсутствующие в настоящее время в Российской Федерации.

С учетом вышеизложенного можно сделать вывод о том, что показатель DTI в настоящее время более применим в качестве агрегирующего показателя для характеристики долговой нагрузки всего населения либо его больших групп (например, работающего населения, экономически активного населения и т.д.) в силу того, что данные для его расчета могут быть получены из имеющейся в стандартной отчетности информации. Для расчета же показателя PTI требуются данные о ежемесячном платеже заемщика, которые практически ни в одной из имеющихся на сегодняшний день форм отчетности не отражены. Однако, как справедливо отмечено экспертами Национального совета финансового рынка, введение показателя PTI при обязательном условии создания необходимой информационной базы в российских условиях стратегически выглядит более предпочтительным с точки зрения предотвращения 
В. И. Маланов. Развитие финансовой грамотности в контексте решения проблемы закредитованности населения Республики Бурятия

снижения текущего уровня жизни граждан ${ }^{1}$. Данный показатель также будет носить более информативный характер и для самих заемщиков, так как с их точки зрения гораздо важнее информация о том, какую часть ежемесячного дохода придется выплатить по взятым кредитам, чтобы рассчитать ту часть дохода, которая останется в распоряжении заемщика, нежели информация об отношении его совокупного долга к совокупному доходу за определенный период.

Во многих странах законодательно введен лимит на долговую нагрузку заемщика (на основе показателя PTI и его производных), которую нельзя превышать. Например, в Литве величина этого лимита составляет 40\%, в Южной Корее - 60\%, в Израиле $-50 \%$, в Сингапуре - 60\%, в Венгрии, $-50 \%$ или $60 \%$ в зависимости от дохода заемщика, в Гонконге - 50\% или $60 \%$ (рассчитывается при выдаче ипотечных кредитов) $)^{2}$.

Принимая во внимание вышеизложенное, в рамках данного исследования был проведен анализ уровня закредитованности населения Республики Бурятия за период 2015-2020 гг. (табл. 1). Необходимо принимать в расчет, что информация о совокупной задолженности населения Республики Бурятия, представленная в официальных статистических отчетных документах, является неполной, так как в показателе «Задолженность по кредитам и займам физических лиц» не отражается задолженность населения по кредитам и займам, выданным микрофинансовыми организациями, ломбардами, кредитными кооперативами, а также лицами, осуществляющими нелегальную ростовщическую деятельность. В настоящее время большинство микрофинансовых организаций, действующих на территории Бурятии, фактически не представляют отчетность регулятору, их деятельность во многом находится вне правового регулирования.

На наш взгляд, более корректно проводить анализ уровня закредитованности населения в расчете трудоспособного населения, при этом нами также рассчитаны показатели закредитованности на душу населения. Задолженность по кредитам и займам на душу населения в Республике Бурятия за период 2015-2020 гг. находится в диапазоне значений от 73 до 99 тыс. p. В 2016 г. наблюдается снижение кредитной задолженности на 12,25\%, или на 10230 р., по сравнению с уровнем 2015 г., однако далее до 2019 г. вновь наблюдается рост на 19\%, или на 15933 р. В 2020 г. данный показатель снизился к уровню 2019 г. на 14,5\%, или на 14416 р. Снижение задолженности по кредитам и займам на душу населения в Бурятии в 2016 г. и 2020 г. не должно вводить нас в заблуждение, поскольку в расчет принимается только та задолженность, которая фигурирует в официальной отчетности кредитных организаций.

\footnotetext{
${ }^{1}$ НП НСФР «Основные элементы системы контроля закредитованности физических лиц с использованием механизма предельно допустимого соотношения совокупного долгового обязательства и дохода (DTI/PTI)». URL: http://rosfinsovet.ru/d/1037448/d/107zpk45-5-11-5osn_elementy_sistemy_dtiptina_ 140317.pdf (дата обращения: 22.03.2021). Текст: электронный.

${ }^{2}$ Банк России. Доклад для общественных консультаций «Об оценке рисков заемщиков-физических лиц на основе показателей долговой нагрузки». URL: http://www.cbr.ru/analytics/ppc/ ConsultationPaper 170221.pdf (дата обращения: 22.03.2021). Текст: электронный.
} 


\section{Таблииа 1}

Уровень закредитованности населения Республики Бурятия за период 2015-2020 гг.*

\begin{tabular}{|l|c|c|c|c|c|c|}
\hline \multicolumn{1}{|c|}{ Показатель } & 2015 & 2016 & 2017 & 2018 & 2019 & 2020 \\
\hline Среднедушевые доходы, p. & 25486 & 25172 & 25040 & 24837 & 25268 & 25615 \\
\hline $\begin{array}{l}\text { Среднемесячная номи- } \\
\text { нальная начисленная } \\
\text { заработная плата, p. }\end{array}$ & 28386,0 & 29969,4 & 32236,5 & 36047,2 & 39115,0 & $\begin{array}{c}41724, \\
2\end{array}$ \\
\hline $\begin{array}{l}\text { Прожиточный минимум } \\
\text { на душу населения, р. }\end{array}$ & 9506 & 9566 & 9777 & 10320 & 11377 & 12283 \\
\hline $\begin{array}{l}\text { Прожиточный минимум } \\
\text { трудоспособного насе- } \\
\text { ления, руб. }\end{array}$ & 9924,00 & 9958 & 10168 & 10731 & 11828 & 12749 \\
\hline $\begin{array}{l}\text { Численность населения, } \\
\text { тыс. чел. }\end{array}$ & 980,4 & 983,2 & 984,3 & 983,9 & 984,6 & 986,0 \\
\hline $\begin{array}{l}\text { Численность трудоспо- } \\
\text { собного населения, тыс. } \\
\text { чел. }\end{array}$ & 412,1 & 559,6 & 551,9 & 544,8 & 538,7 & 549,4 \\
\hline $\begin{array}{l}\text { Задолженность по кре- } \\
\text { дитам и займам на душу } \\
\text { населения, р. }\end{array}$ & 83517 & 73287 & 76073 & 86279 & 99450 & 85034 \\
\hline $\begin{array}{l}\text { Отношение задолженно- } \\
\text { сти на душу населения } \\
\text { по кредитам к средне- } \\
\text { душевым доходам насе- } \\
\text { ления, \% }\end{array}$ & 31 & 24 & 25 & 29 & 33 & 36 \\
\hline $\begin{array}{l}\text { в том числе доля про- } \\
\text { сроченной задолженно- } \\
\text { сти, \% }\end{array}$ & 11,7 & 12,4 & 10,9 & 8,1 & 6,2 & 5,2 \\
\hline
\end{tabular}

*Составлено авторами на основе данных Федеральной службы государственной статистики (www.gks.ru).

По мере накопления просроченной задолженности она списывается и более не фигурирует в официальной отчетности, однако для заемщиков ничего, по сути, не меняется: они так же продолжают платить по просроченным долгам, только теперь уже не банкам, а многочисленным коллекторским агентствам, которые выкупают просроченные долги населения у кредитных организаций. Вероятно, причинами этого могли стать снижение уровня жизни населения, повышение общественного внимания к проблеме закредитованности (проведение круглых столов, семинаров, обсуждение в СМИ) и пр.

Очевидно, что высокий уровень закредитованности населения Республики Бурятия является в том числе и следствием низкой финансовой грамотности ее населения. В настоящее время финансовый аспект жизнедеятельности каждого человека предъ- 
В. И. Маланов. Развитие финансовой грамотности в контексте решения проблемы закредитованности населения Республики Бурятия

являет все больше требований к определенной базе знаний в финансовоэкономической сфере.

Значимость и актуальность рассматриваемого вопроса усиливает факт, что на государственном уровне задачи, связанные с повышением финансовой грамотности населения, включены в перечень приоритетных направлений деятельности. Очевидно, что одним из последствий низкого уровня финансовой грамотности является проблема закредитованности общества.

Для решения проблемы высокой закредитованности населения и повышения уровня его финансовой грамотности необходимо разработать и реализовать комплекс мер, направленных на решение следующих основных задач:

- привлечение общественного внимания к вопросу низкой финансовой грамотности населения и искоренение стереотипа восприятия ее как локальной проблемы;

- проведение образовательных мероприятий на системной основе, способствующих изменению сознания граждан в отношении повсеместно сложившейся практики «жизни в кредит» и трансформации их поведения от «потребительского» к «сберегательному»;

- культивирование активного экономического поведения граждан, соответствующее их финансовым возможностям и основанное на базовых экономических знаниях;

- необходимость координации усилий органов государственной власти, органов местного самоуправления, различных финансово-кредитных институтов, средств массовой информации, образовательных учреждений и домашних хозяйств в вопросе повышения финансовой грамотности;

- создание постоянно функционирующих региональных центров финансового образования, выполняющих координирующую роль в непрерывном образовательном процессе повышения уровня финансовой грамотности населения всех возрастных групп (дошкольная, школьная, средняя профессиональная, вузовская, занятая в экономике, пенсионеры и т. п.) со специализацией по социальным группам.

Лuтература

1. Бурлов Д. Ю., Яковлева И. А. Основные проблемы и направления совершенствования формирования и реализации государственных программ Российской Федерации // Социально-экономическое развитие регионов: проблемы и перспективы: материалы международной научно-практической конференции. Улан-Удэ: Изд-во ВСГУТУ, 2015. Т. 3. С. 106-108. Текст: непосредственный.

2. Бурлов Д. Ю., Яковлева И. А. Современное состояние пенсионного обеспечения и тенденции развития пенсионной системы: региональный аспект // Успехи современной науки. 2016. № 11. С. 123-129. Текст: непосредственный.

3. Бурлов Д. Ю., Яковлева И. А. Эволюционный подход к развитию межбюджетных отношений и особенности их реформирования на современном этапе // Вестник ВСГУТУ. 2016. № 4(61). С. 89-96. Текст: непосредственный.

4. Маланов В. И., Коротыгина К. А. Банковское кредитование населения в Республике Бурятия: «закредитованность» населения // Апробация. 2016. № 3(42). С. 135-138. Текст: непосредственный. 
5. Маланов В. И., Коротыгина К. А. Признание гражданина банкротом: миф или способ борьбы с «закредитованностью» населения // Апробация. 2016. № 11(50). С. 107-109. Текст: непосредственный.

6. Яковлева И. А. Актуальные вопросы развития системы особо охраняемых природных территорий // Фундаментальные исследования. 2015. № 12. Ч. 2. С. 438-443. Текст: непосредственный.

7. Яковлева И. А. Обзор практики формирования доходов бюджета Республики Бурятия // Социально-экономическое развитие регионов: проблемы и перспективы: материалы международной научно-практической конференции. Улан-Удэ: Изд-во ВСГУТУ, 2015. Т. 1. С. 170173. Текст: непосредственный.

8. Яковлева И. А., Халтаева С. Р. Индикативное планирование социально-экономического развития региона // Наука и бизнес: пути развития. 2013. № 11(29). С. 121-123. Текст: непосредственный.

9. Яковлева И. А. Халтаева С. Р. К вопросу оценки результатов выполнения программ социально-экономического развития региона // Наука и бизнес: пути развития. 2014. № 1(31). С. 93-96. Текст: непосредственный.

Статья поступила в редакцию 09.02.2021; одобрена после рецензирования 25.02.2021; принята к публикации 09.04.2021.

\section{DEVELOPMENT OF FINANCIAL LITERACY IN THE CONTEXT OF SOLVING THE PROBLEM OF HOUSEHOLD DEBT LOAD IN THE REPUBLIC OF BURYATIA}

\section{Vitaly I. Malanov}

Student,

Dorzhi Banzarov Buryat State University,

24a Smolina St., Ulan-Ude 670000, Russia

mvi_mmv@mail.ru

Abstract. The article is devoted to the relevant objective of developing financial literacy in the context of solving the problem of household debt load in the Republic of Buryatia. We have studied the existing methodological approaches to the definition of this concept; indicators that characterize the household debt load. The article discusses the causes of debt overburden, with special attention paid to one of the main problems - the low level of financial literacy among population. We have proposed a set of measures to solve the problem of huge debt load of the population in the Republic of Buryatia.

Keywords: financial literacy; household debt load; socio-economic development; living standards; per capita income; average monthly nominal wage; consumer price index; debt to income (DTI).

\section{For citation}

Malanov V. I. Development of Financial Literacy in the Context of Solving the Problem of Household Debt Load in the Republic of Buryatia. Education. Person. Society. 2021; 1: 86-92 (In Russ.).

The article was submitted 09.02.2021; approved after reviewing 25.01.2021; accepted for publication 09.04.2021. 